\title{
Understanding Young Offenders: Developmental Criminology
}

\author{
Sharon Casey*
}

School of Psychology, Deakin University, Australia

\begin{abstract}
The role of criminological theory should be to inform practice. Program developers should start with a recognized theory about the causes of crime and then design interventions that target factors identified in that theory. Unfortunately, the link between theory and practice is not always apparent. In this paper, a number of prominent developmental theories of crime are considered. These theories are significant in that they provide a strong basis for understanding young offending, and how both the criminal justice system and service providers should approach the task of working constructively with those who appear before the court. This is followed by a review of programs that have been designed to address the risk factors identified in these developmental theories.
\end{abstract}

Keywords: Juvenile offending, developmental theories, treatment.

\section{INTRODUCTION}

In simplistic terms, the role of criminological theory is to inform practice, although the reality is that the interface between the two is not always as straightforward as one might hope. What is a theory of crime? And by what process does that theory get translated into practice? The answer to the first question is relatively easy, at least from an academic perspective: A theory is a set of abstract concepts developed regarding a group of facts or events in order to explain them (Engler, 2008). Thus, a theory of crime consists of a set of assumptions (e.g., about human nature, social structure, the principles of causation), a description of the phenomena to be explained (i.e., facts which the theory must fit), and an explanation or prediction of the phenomenon (Bohm, 2001). In order to meet the criterion of being scientific, a theory must be verifiable (i.e., based on empirical observation), compatible (i.e., is consistent with other well-established information), have predictive power (i.e., can generate new ideas through research), parsimonious (i.e., account for the phenomenon in a simple/economic way), and useful (i.e., assists our existence in the everyday world) (Engler, 2009). The second question - how is theory translated into practice - is, perhaps, more difficult to answer. While interventions to reduce offending should be based on knowledge about (1) the causes of crime (i.e., theory), and (2) which programs have been shown to be effective in changing offending behavior (see Gendreau, 2000), it is not always the case that either conditions inform practice. In this paper, a number of prominent developmental theories of crime are considered. These are significant in so far as they provide the basis for understanding young offending, and how both the criminal justice system and service providers should approach the task of working constructively with those who appear before the court.

*Address correspondence to this author at the School of Psychology, Deakin University, PO Box 630, Oakbank South Australia 5243, Australia; Tel: +61 35227 8715; Fax: +61 35227 78621; E-mail: sharon.casey@deakin.edu.au
A useful starting point here is to consider the "theories" that Latessa, Cullen and Gendreau (2002, p.44) found were either implicit in programs observed by them or identified by agency staff as the crime causing factors their programs were targeting.

- "Been there, done that" theory

- "Offenders lack creativity" theory

- "Offenders need to get back to nature" theory

- "It worked for me" theory

- "Offenders lack discipline" theory

- "Offenders lack organizational skills" theory

- "Offenders have low self-esteem" theory

- "We just want them to be happy" theory

- The "treat offenders as babies and dress them in diapers" theory

- "Offenders need to have a pet in prison" theory

- "Offenders need acupuncture" theory

- "Offenders need to have healing lodges" theory

- "Offenders need drama therapy" theory

- "Offenders need a better diet and haircut" theory

- "Offenders (male) need to learn how to put on makeup and dress better" theory

- "Offenders (male) need to get in touch with their feminine side" theory

As noted by the authors, the list would be cause for amusement but for the frequency with which such "theories" underpinned programs provided in correctional settings. Indeed, similar ideas are commonly expressed by those who work with juvenile justice clients in Australia. Interventions are frequently based on what practitioners see as "common sense" or on their own personal experience and/or clinical 
knowledge, and practitioners often begin work in youth justice settings with relatively little formal training in understanding why young people offend. Latessa and his colleagues (2002) use the example of boot camps (intensive residential training programs for offenders, often run on para-military lines) to illustrate how the failure to consider theory and apply this to practice can not only be detrimental to both offender and victim, but can also become a costly exercise in financial terms:

- "Based on a vague, if not unstated theory of crime, and an absurd theory of behavioral change ('offenders need to be broken down' - through a good deal of humiliation and threats - and then 'built back up'), boot camps could not possibly have 'worked'. In fact, we know of no major psychological theory that would logically suggest that such humiliation or threats are components of effective therapeutic interventions. Even so, boot camps were put into place across the nation without a shred of empirical evidence as to their effectiveness, and only now has their appeal been tarnished after years of negative evaluation studies. How many millions of dollars have been squandered? How many opportunities to rehabilitate offenders have been forfeited? ..." (p.44; references removed for clarity).

In developing a program, practitioners should therefore start with a recognized theory about the causes of crime and then proceed to design an intervention to target the factors identified in that theory (Andrews \& Bonta, 1998). The review that follows considers some theories of crime that are not only useful in explaining the aetiology of offending but also take into account the developmental changes that are the hallmark of adolescence. This is followed by a review of programs that have been designed to address the risk factors identified in these theories. While at times some aspects of the various approaches may appear repetitive, there are subtle - and important - differences in aetiology that necessarily require consideration.

\section{THEORIES OF CRIME}

Many theories have been postulated to explain the causes and correlates of criminal behavior. Given the breadth of this research, attempts have been made to thematically organize these. One particularly useful organising scheme is that proposed by McGuire (2002), which consists of five discrete but interconnected levels moving from large-scale, macro accounts of crime at Level 1 (e.g., conflict theory, strain theory), through locality-based accounts at Level 2 (e.g., differential opportunity theory), socialization and group influence processes at Level 3 (e.g., sub-cultural delinquency theory, differential association theory, social learning theory), crime events and "routine activities" at Level 4 (e.g., routine activity theory, rational choice theory), to individual factors at Level 5 (e.g., neutralization theory, psychological control theories, cognitive social learning theory). Many of these theories of crime are, however, static in nature. They fail to provide a sufficient level of explanation for the varying patterns of behavior that sees some young people never commit crime, some desist from crime at an early age, and a small percentage of offenders continue their criminal behavior into adulthood $^{1}$.

One of the most stable empirical findings to emerge from decades of criminological research is the relationship between age and crime. Criminal behavior is relatively uncommon in children less than ten years of age, despite many children displaying what have been described as 'precursor behaviors' during this developmental period (Thornberry, 1997). The onset of actual delinquent and criminal behavior occurs in late childhood and early adolescence (around the ages of 10 to 14), with the prevalence of criminal involvement peaking during the middle to late adolescent period (i.e., 16 to 17 years of age), followed by a rapid decline and subsequent tapering off for most by the early twenties (Farrington, 1995a; Moffitt, 1993). An important observation here is that minor delinquency during adolescence is statistically normative (Ayers, Williams, Hawkins, Peterson, Catalano, \& Abbott, 1999), and only a small proportion of young people continue their criminal careers well into adulthood.

An alternative approach to explaining crime is that offered by developmental and life-courses (DLC) theories of offending (e.g., Catalano \& Hawkins, 1996; Farrington, 2005a; Moffitt, 1993, 1997; Sampson \& Laub, 1997, 2005; Thornberry, 1997). Developmental theories are dynamic rather than static, and are effectively concerned with three main issues: the development of offending and antisocial behavior, risk and protective factors at different ages, and the effects of life events on the course of development. More importantly, from a rehabilitative perspective at least, DLC approaches document and explain within-individual variations in offending throughout life; an approach that is more relevant to causes, prevention, and treatment than the between-individual variations articulated in many of the static theories (e.g., the demonstration that unemployed people commit more crimes than employed people). The utility of the DLC approach was recently highlighted by Farrington (2007, p.125) who noted that:

- "DLC theories usually assume that within-individual variations over age in measured offending reflect within-individual variations with age in an underlying theoretical construct such as antisocial potential or criminal propensity. They suggest that the frequency of offending at any age depends not only on the strength of the underlying construct but also on environmental factors such as opportunities and on cognitive (decisionmaking) processes. Hence, desistance should be influenced by all of these factors".

From a DLC perspective, the focus is on life experiences that mould the individual and send him or her along a particular trajectory or pathway. The various theories generally agree that human development can be understood in terms of four interrelated and fused dimensions (Tobach \& Greenberg, 1984). The first is the principle of relative plasticity, which stipulates that the potential for change exists across the lifespan. Second, DLC theorists support the view that the bases for change lie in the relationships that occur within the

\footnotetext{
${ }^{1}$ For example, while strain or social control theories may explain the process of forming attitudes, values, or attachments that allow or disallow behaviors that violate the law, these theories are less helpful in terms of (a) explaining how these factors change during the life-course and (b) if they do not change, why most delinquents desist and only a few go on to commit adult crimes.
} 
multiple levels of organisation that constitute human life. Despite variations in how these levels have been conceptualized (e.g., Bronfenbrenner, 1979; Ford \& Lerner, 1992; Sameroff, 1983), there is a general consensus that they include the biological, individual/psychological, social relational (i.e., families, peer groups, social networks) and sociocultural (e.g., governments, schools, churches) levels. The third principle is the understanding that no level of human organisation functions in isolation, but rather, each level functions as a consequence of its fusion or inter-relation with other levels. This interdependence means that change at any one level will impact upon continuity or discontinuity at another level. Finally, given the dynamic nature of the interaction between these levels of human organisation, individual development is embedded in the historical period of study. Notwithstanding this temporality and individuality, differences within and across all levels are seen as having core and substantive significance with respect to the general understanding of human development.

What the developmental/dynamic perspective illustrates is that criminal behavior is too heterogeneous to be explained by a common set of factors. A DLC approach assumes that different factors may have different effects on the individual offender at different ages. Moreover, such an approach argues that crime data actually contradicts an ageinvariant position which maintains that (1) all antisocial behavior peaks in late adolescence; (2) there is no substantive individual, cohort, historical, or cultural differences in this relationship; and (3) all antisocial behavior declines sharply and continuously throughout life (Sampson \& Laub, 1995). Thus in attempting to understand the continuity and stability of offending behavior across the life-span, DLC theorists explore transactions between individual characteristics (e.g., cognitive abilities, temperament) and age-graded developmental contexts such as social factors (e.g., family and peer relations, school, employment), that can mediate both proand antisocial pathways.

Thornberry (1997) has described what he sees as the major advantages to adopting a DLC approach to crime. First, he points out that non-developmental approaches fail to identify and offer explanations for many important aspects of crime, including prevalence; age of onset; duration of offending career; escalation and de-escalation in terms of frequency and serious of criminal involvement; and, finally, desistance from crime. Second, while non-developmental approaches examine different causal structures for particular types of offenders (e.g., violent versus non-violent), there is a failure to identify types of offenders based on developmental considerations (e.g., life-course-persistent versus adolescent-limited offending). DLC approaches offer a way to explain the criminological conundrum that whereas most antisocial children are not destined to become antisocial adults, antisocial adults are most often antisocial children. Third, non-developmental paradigms do not sufficiently examine the precursor behavior of the young (e.g., conduct disorder and antisocial behavior) or the outcomes of such behavior. Finally, non-developmental approaches neglect to relate developmental changes, including trajectories and transitions, of the life course as it relates to delinquent behavior.

The DLC approaches described below can be placed within Loeber and LeBlanc's (1990) conceptual framework for the development of juvenile offending (see Table $\mathbf{1}$ below). Where they differ most is their explanations of desistance. Farrington (2005a), for example, has argued that desistance is dependent upon a decrease in antisocial potential caused by life events (e.g., marriage, stable employment), while Catalano and Hawkins (1996) see desistance as a function of changes in opportunities, rewards, costs, and bonding that are influenced by life events. Sampson and Laub (2005) have argued that it depends on increased social controls and structured routine activities that emerge when an individual marries, obtains steady employment, or joins the military, while and Moffit (1997) proposes that desistance is a function of adolescent limited offenders achieving adult goals (e.g., material goods) and life events, whereas life-course persistent offenders fail to desist, at least in part, because they select antisocial partners and jobs. (Table 1).

Table 1. Loeber and Le Blanc's (1990) Core Concepts of Developmental Criminology

\begin{tabular}{|l|l|l|}
\hline \multicolumn{3}{|c|}{ Concepts } \\
\hline \multicolumn{1}{|c|}{ Generic } & Temporal Boundary & \multicolumn{1}{c|}{ Dynamic } \\
\hline \hline Participation & Age of onset & Activation: \\
Lambda & Age at termination & Acceleration \\
(frequency) & Duration & Diversification \\
Crime mix & Transfer/crime & Stabilisation \\
Seriousness & switching & Maintenance \\
Variety & & (Aggravation) \\
& & Escalation \\
& & Developmental \\
& & Sequence \\
& & Desistance \\
& & Deceleration \\
& & De-escalation \\
& & Reaching a ceiling \\
& & Specialisation \\
\hline
\end{tabular}

\section{Moffitt's Developmental Taxonomy}

Moffitt's (1990, 1993, 1997; Caspi, \& Moffitt, 1995) developmental taxonomy of antisocial behavior posits two discrete types of young offender: adolescence-limited and life-course persistent. The taxonomy is based on research that investigated base rates of persistent and temporary antisocial behavior in a cohort of 1,037 children in Dunedin, New Zealand who were born between 1972 and 1973. Moffitt found that approximately $5 \%$ of the total sample could be identified as engaging in antisocial behavior that was more than one standard deviation above the average of ratings at each of seven biennial assessments at ages three, five, seven, eleven, thirteen, and fifteen. This contrasted with around two-thirds of the remaining sample being rated as above average on antisocial measures (a) at age one or two, or (b) by only one reporting agent. Thus Moffitt concluded a significant difference between the two groups in terms of the stability of antisocial behavior, and proposed her two distinct pathways leading to delinquency. 
The majority of young offenders can be considered adolescence-limited, and while this group may become involved in very serious crime, they do not engage in delinquent behavior prior to or after adolescence. According to Moffitt (1995), adolescence-limited offenders generally have the capacity to suppress antisocial impulses and are, on the whole, law-abiding citizens. Rather than being maladjusted, Moffitt sees this group of young people as exhibiting processes of social mimicry, motivated by a desire to demonstrate maturity and personal independence. For the most part, they engage in low-level offenses (e.g., alcohol use, shoplifting, vandalism), that represent rebelliousness rather than violent forms of delinquency (see McCabe, Hough, Wood \& Yeh, 2001; Nagin, Farrington, \& Moffitt, 1995; and Piquero \& Brezina, 2001 for an empirical assessment of adolescentlimited offending patterns). Over time, the adolescencelimited offender experiences a lack of motivation for delinquency as biological and social age converge on the path to adulthood (i.e., they exit the "maturity gap"; Moffitt, 1997, p.26).

In contrast, life-course persistent offenders manifest antisocial behaviors at an early age (Henry, Caspi, Moffitt, \& Silva, 1996; Moffitt, 1993, 1997; Moffitt \& Caspi, 2001). This small group of offenders - approximately $5 \%$ - is characterized by persistence in problem behavior from childhood through adulthood, with different manifestations of that problem behavior during different stages of development. Their life-course pattern of offending is said to be linked to pre- and peri-natal conditions and factors associated with adverse child rearing conditions during early childhood. According to Moffitt, two types of neuropsychological deficits verbal intelligence (i.e., reading ability, receptive listening, problem-solving skill, memory, speech articulation, and writing) and executive function (manifested as inattention, hyperactivity, and impulsivity) - give rise to an array of antisocial behaviors. Children with neuropsychological deficits are restless, fidgety, destructive, and noncompliant, using violent outbursts rather than conversation. The persistence of antisocial behavior over time is attributed to these early problem behaviors tending to limit the child's opportunities for learning pro-social behavior during formative developmental stages and, as a result, problem behaviors become increasingly entrenched. Moreover, because these behaviors persist into adulthood, they may continue to increase the probability of adult antisocial behavior in a "proximal contemporary fashion" (Moffitt, Lynam, \& Silva, 1994).

\section{Sampson and Laub's Age-Graded Theory of Informal Social Control and Cumulative Disadvantage}

One of the most dominant developmental theories is Sampson and Laub's (1993, 1997, 2003, 2005) age-graded theory of informal social control and cumulative disadvantage. Based on findings from the analysis of archival data originally collected by Glueck and Glueck (1950) and a matched comparison group, the theory postulates that informal social controls (e.g., involvement in family, work, school) mediate structural context and explain criminal involvement, even when an underlying level of criminal propensity exists. Crime is said to be more likely when social bonds to society are weakened or broken. More specifically, informal social controls, which stem from the social relations between individuals and institutions at each stage of the life course, are characterized as a form of social investment or social capital (see Coleman, 1988). Social capital "includes the knowledge and sense of obligations, expectations, trustwothiness, information channels, norms, and sanctions that these relations engender (Hagan, 1998, p.503). In essence, bonds to society create social capital and interdependent systems of obligations that make it too costly to commit crime (Sampson \& Laub, 1993). The individual garners variable amounts of social capital from informal social control networks, which, in turn, explains the continuity in antisocial behaviors across various life stages. Those individuals who are low in social capital (and who have past criminal involvement) "mortgage" future life changes. This process is the cumulative disadvantage referred to in the theory. Prosocial adult social bonds (or turning points), can serve to "right" previously deviant pathways (e.g., juvenile delinquency, unemployment, substance abuse) and thereby place the individual on a trajectory towards more successful outcomes. According to Sampson and Laub, criminal careers are characterized by change and dynamism: even the most active offender desists over the life course (e.g., a 60 year old criminal is not as active and violent as they may have been at 17; see Sampson \& Laub, 1993, p.114).

Empirical analysis (e.g., Sampson \& Laub, 1993) has provided support for the notion of continuity in offending over the life course. For example, in the matched comparison group used in the reanalysis of the Glueck and Glueck (1950) data, there was strong evidence for homotypic continuity from childhood to adulthood among delinquents. For example, arrests in early and middle adulthood were greater for the delinquent sub-sample than for the non-delinquents, with $76 \%$ of delinquents arrested between ages 17 and 25 and only $20 \%$ of non-delinquents arrested over the same age period. These percentages remain similar when arrests for ages 32 to 45 are compared (55\% and $16 \%$ for delinquents and non-delinquents respectively). Heterotypic continuity was also evident among the Glueck and Glueck delinquent sample. For example, among those who served in the military, $60 \%$ of the delinquents were charged with an offense during their term of service compared with $20 \%$ of nondelinquents. The delinquents were also found to be more likely, among other things, to have a dishonourable discharge, less likely to have finished high school, and more likely to have low job stability. This continuity has been explained in terms of both childhood propensity and cumulative disadvantage, with Sampson and Laub describing continuity as "cumulative, developmental model whereby delinquent behavior has a systematic attenuating effect on the social and institutional bonds liking adults to society (for example, labor force attachment, marital cohesion) ..." (1993, p. 138).

Despite this continuity, Sampson and Laub's research (e.g., 1993, 1997, 2003, 2005) has also shown that change in criminal behavior occurs due to variation in the strength of adult social bonds stemming from life events, such as cohesive marriage, stable employment, and serving in the military, which is independent of criminal propensity. In their view, it is the quality of the relationship or "the social investment or social capital in the institutional relationship, whether it involves family, work, or community setting, that dictates the salience of informal social control at the individual level" (Sampson \& Laub,1993, p.1993, pl14). In consid- 
ering the impact of incarceration and its indirect influence on future crime, they propose that it facilitates crime via subsequent job instability (Sampson \& Laub, 1993, 1997; Laub \& Sampson, 1995).

\section{Farrington's Integrated Cognitive Antisocial Potential (ICAP) Theory}

Farrington (2005b) has recently developed the Integrated Cognitive Antisocial Potential (ICAP) theory to explain how early risk factors for antisocial behavior, previously identified in longitudinal research such as the Cambridge Study (e.g., Farrington, 1992, 1995b, 2003) can be incorporated into a coherent developmental theory of crime. An integration of ideas from a range of other theories including strain, control, learning, labelling and rational choice approaches (see Cullen \& Agnew, 2003), the key construct is antisocial potential (AP), defined as the potential to commit antisocial acts. The underlying assumption is that "the translation from antisocial potential to antisocial behavior depends on cognitive (thinking and decision-making) processes that consider opportunities and victims" (Farrington, 2005b, p.184). AP can be viewed as both a long- and short-term phenomenon, with long-term, persisting, between-individual differences distinguished from short-term within-individual variations. For example, long-term AP depends on impulsiveness, strain, modelling, socialization processes, and life events, whereas short-term variations are dictated by motivating and situational factors (e.g., angry, drunk). Individuals with high levels of AP are at risk for offending over the life-course, while those with low levels tend to live more conventional lives. Given that relatively few people experience high levels of AP, the distribution of chronic offenders in the population at any age is both limited and highly skewed.

The model postulates a tendency for long-term AP individuals to commit many different types of antisocial acts including different types of crime (thus offending and antisocial behavior is seen as versatile rather than specialized). And while AP levels are fairly consistent over time, they peak in teenage years because of the effects of maturational factors that directly influence crime rates (e.g., increase in peer influence and decrease in family influence). The risk factors hypothesized to influence long-term AP are the desire for material goods, status among intimates, excitement and sexual satisfaction (factors which are consistent with strain theory). However, these motivations only lead to high AP if the individual habitually chooses antisocial methods of satisfying them. Consequently, offending is the outcome of antisocial methods being used by those who find it difficult to satisfy their needs legitimately (e.g., individuals on low incomes, the unemployed, and those who fail at school). However, the model posits that the methods an individual chooses will also depend on their physical capabilities and behavioral skills (e.g., a five-year-old would find it difficult to steal a car).

Long-term AP is also said to depend on attachment and socialization processes. For example, AP will be low if parents consistently and contingently reward good behavior and punish that which is considered bad (although children with low anxiety are thought to be less well-socialized as they have fewer concerns about parental punishment); if children are not attached to (prosocial) parents (e.g., if parents are cold and rejecting) and if the individual is exposed to and influenced by antisocial models (e.g., criminal parents, delinquent siblings, delinquent peers). Long-term AP is also high in impulsive individuals (as they tend to act without thinking about the consequences), and influenced by life events (e.g., it decreases - at least for males - after marrying or moving out of high crime areas and increases after separation from a partner).

In terms of explaining offending behavior and other types of antisocial acts, the ICAP theory suggests it is an interaction between the individual (and immediate level of AP) and the social environment (in particular criminal opportunities and victims). By contrast, short-term AP varies within individuals according to short-term energizing factors (e.g., being bored, angry, drunk, or frustrated, or being encouraged by male peers). Criminal opportunities and the availability of victims depend on routine activities, for example, encountering an opportunity or victim may cause a short-term increase in AP; a short-term increase in AP may also motivate a person to seek out criminal opportunities and victims. However, the likelihood that a crime is committed in a particular context (for a given level of AP) is dependent upon (a) cognitive processes, including an assessment of the subjective benefits (e.g., the goods to be obtained) and costs (e.g., being caught by the police, parental disapproval) and (b) the individual's stored behavioral repertoire or scripts (based on past experience). As a result of the learning process, changes may be made to long-term AP and future cognitive decision-making processes. This is more likely when the consequences are either reinforcing (e.g., gaining material goods or peer approval) or punishing (e.g., legal sanctions or parental disapproval). Furthermore, if the consequences involve labelling or stigmatizing the offender, it may be more difficult to legally achieve one's aim and, as a consequence, may serve to increase AP.

\section{Catalano and Hawkins Social Development Model}

Catalano and Hawkin's (1996) Social Development Model is based on research that has integrated the role of risk and protective factors for behavior such as delinquency and substance use, but may also be applied to the onset of other antisocial or risk behaviors. The authors have argued that antisocial behaviors such as delinquency and drug use are initiated in childhood or early adolescence, and because early onset predicts the seriousness and persistence of such problem behaviors a theory that seeks to explain the onset, maintenance, and desistence from such behaviors should focus on causal processes in childhood development. The Model posits that an individual learns pro- or antisocial behavior through the socialising agents of family, school, peers, and community. Four main factors are seen as necessary for socialisation to occur: there must be perceived opportunities for involvement in activities and interactions with others, followed by the level of involvement and interaction engaged in and experienced by the individual. Successful involvement will be influenced by the skills the individual possesses, and finally the outcome of the interaction will provide reinforcement for the involvement (see Ayers et al., 1999; Catalano \& Hawkins, 1996; Catalano \& Kosterman, 1996). 
Critical in the development of pro- or antisocial behavior is process of socialisation, through which individuals form bonds with agents of socialisation such as parents, peers, school, and the wider community (Catalano \& Hawkins, 1996). A social bond forms when the socialisation processes are consistent; that is, when reinforcement (reward) is consistent with that received for previous, similar involvements with the social unit. Each social unit has a set of norms, beliefs, and values that are common among the majority of its members. The bond an individual forms with a particular socialisation agent determines attachments to other people within that group, belief in the values of the unit, and the level of commitment or investment the individual has toward adhering to or supporting the norms and values of the unit (Catalano \& Kosterman, 1996). Thus social bonds produce informal controls that influence future behaviors: In order to preserve a bond the individual must conform to the norms and values of that unit; any behavior that does not conform to group norms and values jeopardizes this bond, while conformity is rewarded with its preservation (Catalano \& Hawkins, 1996). The strength of the attachment to the social unit is determined by the level of reinforcement the individual perceives as forthcoming in response to their involvement with the group. Rewards are determined by the skills and ability the person possesses that enable them to engage with the socialising unit (Catalano \& Hawkins, 1996; Catalano \& Kosterman, 1996).

According to Catalano and Kosterman (1996), attachment outcomes depend on the socialisation pathway that the attachment produces. The antisocial path of socialisation is produced in a number of ways. First, a strong attachment to antisocial others, through the process described above, will result in the individual committing to the antisocial values of the group to which they have bonded. Second, a weak bond to pro-social units will result in diminished rewards for maintaining that bond, the consequences of which is the reduction in negative outcomes for contravening group norms and values. A third means by which antisocial behaviors are produced involves a cost-benefit analysis of the intended behavior which indicates that there is low risk associated with the behavior. The individual may perceive that there is little likelihood of their antisocial behavior being discovered by others, and thus the threat to the social bond is minimal. Thus the Social Development Model assumes that factors that influence the nature, strength, and quality of social attachments in the domains of family, peers, school, and community ultimately determine the manifestation (or lack thereof) of antisocial behaviors.

\section{RISK AND PROTECTIVE FACTORS}

A view of delinquency as a developmental process has enabled DLC theorists to identify an array of risk factors that either precede or co-occur with its development. Some risk factors appear to be implicated - directly or indirectly - in the underlying causes of problem behavior; others are symptoms or 'markers'. While it is clear that no single risk factor can be said to 'cause' delinquency, reviews and further statistical analyses have served to narrow the field and point to those most likely to contribute to interlinked chains of causation (see, for example, Loeber et al. 2003; Farrington, 2004, 2007). Risk factors can relate to individual children and young people, to their families, to their schooling and to the communities in which they live (see Table 2). It is also clear that different combinations of risk factors contribute to different cumulative effects and that the overall risks of antisocial behavior can increase exponentially depending on the number of risk factors to which children are exposed.

In Australia, the developmental approach informed the Pathways to Prevention report (Homel et al., 1999), which sought to develop a policy framework whereby early intervention and the targeting of risk factors in key developmental stages, might have an impact upon delinquency and other social problems. The authors articulated risk along a continuum that moves through remote risk, high risk, and imminent risk, ending with the group of young people defined as "at-risk", who are actively engaging in dangerous behaviors, and experiencing extreme vulnerability. Those at the extreme points on the at-risk continuum are more likely to experience multiple future events, which decreases their chances of developing and sustaining satisfying, fulfilling, and responsible lives. Moreover, it has been argued that "at-risk" adolescents are much more likely to develop antisocial behaviors, to abuse alcohol and drugs, to experience unwanted teen pregnancy, to drop out of school, and to be both the perpetrators and the victims of personal violence.

Another consequence of adopting a developmental approach to explaining delinquency has been the theoretical attention paid to influences that might serve as a 'buffer' between risk factors and the onset of delinquency. These influences, known as protective factors, are thought to mediate or moderate outcomes following exposure to risk factors, often resulting in a reduced incidence of problem behavior. In fact, a model of cumulative protection has been proposed by Yoshikawa (1994), who argues that the effects of early family support and education extend beyond the known short-term impact on risk factors (e.g., parenting quality, child cognitive ability, parental education status, family size, family income), and could explain why chronic juvenile delinquency can be amenable to change. A list of protective factors in provided in Table 3. And while knowledge about protective factors is less extensive and well-developed than the literature concerning risk, it is nonetheless apparent that protective factors may work by (1) preventing risk factors from occurring in a child's life, (2) by interacting with a risk factor to attenuate its effects, or (3) by breaking the mediating chain by which risk leads to negative behavior (Table 3 ).

There is still much to be learned about the salience of risk and protective factors at different stages in children's development and the direct or indirect mechanisms by which they influence behavior. Developmental sequencing also needs to be better understood, although it would seem that some factors, such as poor parenting are significant from the start of children's lives, whereas others, like association with negative peers, assume greater importance nearer adole-scence.

\section{INTERVENTIONS FOR ANTISOCIAL AND DELIN- QUENT BEHAVIORS}

A DLC approach has much to offer in terms of identifying risk factors that may cause delinquency for particular young people at specific stages of their development. How- 
Table 2. Risk Factors for Delinquency and Other Antisocial Behavior

\begin{tabular}{|c|c|c|}
\hline Level & Risk Factors \\
\hline \hline Child & $\begin{array}{r}\text { Poor problem solving; Beliefs about aggression; Attributions; Poor social skills; Low self-esteem; Lack of empathy; Alienation; } \\
\text { Hyperactivity/disruptive behavior; Impulsivity; Prematurity; Low birth weight; Disability; Prenatal brain damage; Birth injury; Low } \\
\text { intelligence; Difficult temperament; Chronic illness; Insecure attachment. }\end{array}$ \\
\hline Familial & $\begin{array}{c}\text { Psychiatric disorder, especially depression; Substance abuse; Criminality; Antisocial models; Family violence and disharmony; Marital } \\
\text { discord; Disorganized negative interaction/social isolation; Parenting style; Poor supervision and monitoring of the child; Discipline } \\
\text { style (harsh or inconsistent); Rejection of the child; Abuse; Lack of warmth and affection; Low involvement in child's activities; } \\
\text { Neglect; Teenage mothers; Single parents; Large family size; Father absence; Long-term parental unemployment. }\end{array}$ \\
\hline School & $\begin{array}{r}\text { School failure; Normative beliefs about aggression; Deviant peer group; Bullying; Peer rejection; Poor attachment to school; Inadequate } \\
\text { behavior management. }\end{array}$ \\
\hline Life events & $\begin{array}{c}\text { Divorce and family break-up; War or natural disasters; Death of a family member. } \\
\text { Community and } \\
\text { social factors }\end{array}$ & $\begin{array}{c}\text { Socio-economic disadvantage; Population density and housing conditions; Urban area; Neighbourhood violence and crime; Cultural } \\
\text { norms concerning violence as acceptable response to frustration; Media portrayal of violence; Lack of support services. }\end{array}$ \\
\hline
\end{tabular}

Source: adapted from Homel et al. (1999).

Table 3. Protective Factors Associated with Delinquency and Other Antisocial Behavior

\begin{tabular}{|c|c|}
\hline Level & Risk Factors \\
\hline \hline Child & $\begin{array}{r}\text { Social competence; Social Skills; Above average intelligence; Attachment to family; Empathy; Problem solving skills; Optimism; } \\
\text { School achievement; Easy temperament; Internal locus of control; Moral beliefs; Values; Self-relative cognitions; Good coping style.. }\end{array}$ \\
\hline Familial & $\begin{array}{r}\text { Supportive caring parents; Family harmony; More than two years between siblings; Responsibility for chores or required helpfulness; } \\
\text { Secure and stable family; Supportive relationship with other adult; Small family size; Strong family norms and morality.. }\end{array}$ \\
\hline School & $\begin{array}{r}\text { Positive school climate; Pro-social peer group; Responsibility and required helpfulness; Sense of belonging/bonding; Opportunities for } \\
\text { some success at school and recognition of achievement. }\end{array}$ \\
\hline Life events & Meeting significant person; Moving to a new area; Opportunities at critical turning points or major life transitions.. \\
\hline $\begin{array}{c}\text { Community and } \\
\text { social factors }\end{array}$ & $\begin{array}{r}\text { Access to support services; Community networking; Attachment to the community; Participation in church or other community group; } \\
\text { Community/cultural norms against violence; A strong cultural identity and ethnic pride. }\end{array}$ \\
\hline
\end{tabular}

ever, a developmental risk approach is not without its problems. In addition to problems associated with establishing which risk factors might be considered causal, Farrington (2000) also cites difficulties associated with “...choosing interventions based on identified risk and protective factors, in evaluating multiple component and area-based interventions, and in assessing the effectiveness and cost-effectiveness of components of interventions" (p.16). An additional difficulty - particularly from a practitioner's standpoint - is that criminological theorists offer little in terms of the types of interventions (primary, secondary, or tertiary) that serve to ameliorate risk and, where multiple risks exist, the order in which risk factors need to be addressed. The practitioner is thus left with the task of identifying not only which interventions work best in terms of changing antisocial and delinquent behavior but also, given the developmental differences in young people who come to the attention of the juvenile justice system, how best to intervene for a particular individual with a specific set of risk factors.

The challenge for practitioners is that all interventions do not work equally well and, moreover, tend to work best when interventions respond to the specific needs of the young person (Hoge, 2001; Lipsey \& Wilson, 1998). In the current rehabilitation climate, this difficulty has been addressed by adopting an "evidence-based practice" approach that relies on research which has identified the most effective interventions. What is put forward as best practice can, however, vary considerably with respect to that which constitutes the respective practice and how well it is anchored in research evidence. According to Howell and Lipsey (2004), the link between the two can be loose with few claims of evidence-based practice supported by convincing documentation of the relevant evidence and procedures. A review of the published literature supports this supposition. That said, practitioners must nevertheless rely on the available research to make decisions about intervention programs and in applying research knowledge to program practice, typically takes one of three approaches. The most popular strategy involves the replication of "model programs" shown via research and demonstration to have achieved positive results. This requires that local programs be well-defined and documented and implemented with a high degree of fidelity. A second strategy for applying research results to program practice is to directly evaluate the effectiveness of existing programmes. Credible assessments of program impact on the 
probability of re-offending will ensure that effective programmes are maintained and supported while ineffective programs are eliminated or redesigned and re-evaluated. The third approach involves extracting the program principles from the guidelines for effective interventions from the research, in particular previous evaluations of relevant programs, and applying these to practice. This strategy does not require that each program replicate all aspects of an effective research and development program with consistent high fidelity or that regular outcome evaluation be undertaken to provide feedback. However, it does provide a sufficient body of evaluation research and a valid identification of the features that differentiate between effective programs from ineffective ones.

What then does research say about the most effective programs? Meta-analytic ${ }^{2}$ reviews have been conducted to identify the effectiveness of a large number of delinquency prevention and intervention programs. The end result has been largely encouraging. For example, the overall average effect on recidivism for evaluations that have used control group designs is positive and statistically significant, although of a somewhat modest magnitude (see Lipsey, 1992, 1995; Lipsey \& Wilson, 1998). Of greater interest is the large variation around the average effect size, which indicates that the effects of some programs are quite sizeable while those of others negligible or even negative (Lipsey \& Wilson, 1998). Lipsey's $(1992,1995)$ initial meta-analysis of 400 intervention programs showed that recidivism was reduced by approximately $10 \%$ for juveniles who completed intervention programs as compared to those who did not. This reduction increased to $40 \%$ for the best interventions, the most effective of which focussed on changing overt behavior through structured training or cognitive-behavioral interventions designed to improve social development skills (i.e., interpersonal relations, self-control, school achievement, and specific job skills). These program effects for structured, behavioral, and/or skill-building interventions were shown to be consistently higher than for insightoriented approaches, such as casework, counselling, and group therapy.

A second meta-analysis undertaken by Lipsey and Wilson (1998) focussed on 200 program interventions for serious and violent offenders delivered to young offenders in both institutional and non-institutional settings. The analyses examined the relationship between effect sizes and four categories of variables: (a) characteristics of the individual (e.g., proportion with prior offenses, prior indications of aggressive behavior, mean age, gender, ethnic mix), (b) general program characteristics (e.g., age of program, program provider), (c) treatment type (e.g., counselling, behavioral programs, multiple services), and (d) the amount of treatment (e.g., average number of weeks from first to last treatment, ratings of treatment integrity). While interpersonal skills

\footnotetext{
${ }^{2}$ Meta-analysis is a quantitative technique for coding, analysing, and summarizing research evidence. The magnitude of the intervention effects of the studies under review is represented with statistics known as "effect sizes," e.g., the magnitude of the difference between the mean values on the outcome variable like recidivism for the individuals receiving intervention and those in the control group (Lipsey and Wilson, 2001). Effect sizes are then analysed in various ways, for example, summarized as overall means or compared for different groups of studies. This method of synthesising research enables a researcher to examine a wide range of programme evaluations, and a great deal of coded detail about each, in a systematic and relatively objective manner.
}

training was found to be effective in either setting, there were important differences in the kinds of interventions found to be effective in the two settings. For noninstitutionalized offenders, three other types of treatment showed the most positive effects: individual counselling, behavioral interventions, and multiple services. By comparison, the four most effective treatment for institutionalized offenders were teaching family homes (i.e., behavior modification in community-based homes), behavioral programs, community-residential interventions (i.e., therapeutic communities), and multiple services. As was the case the earlier meta-analysis, the average effective size was small (.12) but with considerable variation around the mean. The most effective treatments for institutionalized offenders showed a $30-35 \%$ reduction in recidivism, with a $30 \%$ reduction for non-institutionalized offenders. And contrary to the commonly expressed view that more serious offenders are the least amenable to treatment, the biggest treatment gains were found for those at the upper end of the seriousness scale.

Howell and Lipsey (2004) have recently concluded that the concept of "best practice" is not necessarily a "set of program models to be emulated" (p.42). Based on findings from Lipsey's (1992, 1995; Lipsey \& Wilson, 1998, 2000) meta-analytic reviews, they argue that best practice refers to "a differentiated set of program elements, many combinations of which are associated with positive outcomes" (p.42). They cite the four major features of effective juvenile programs to emerge from Lipsey's meta-analytic work as follows:

- Primary services: the effectiveness of the main service focus of a program, independent of its use with another intervention;

- Supplemental services: adding another service component to the primary service may, but often does not, increase its effectiveness;

- Service delivery: the amount and quality of service provided, as indicated in service frequency, program duration, and extent of implementation; and

- Characteristics of juvenile clients: some programs are more effective for high-risk juveniles than for low risk, and vice versa; others are more effective for older or younger offenders.

In conclusion, DLC theories have much to offer the development of effective programs for young offenders. A consideration of developmental and life course factors is likely to be critical if the criminal justice system is to respond to the needs of children and young people who commit crime in a meaningful, and ultimately, effective, manner. Too often, programs and interventions that have been developed either for young children or for adults are adapted for use with adolescents, and insufficient attention is paid to the developmental differences that exist between groups of young offenders. The effectiveness of such interventions can be further enhanced when preceded by an assessment of risk for re-offending. Actuarial methods of assessment (e.g., Youth Offender Level of Supervision, Inventory, Shields, 1993; Youth Level of Services Inventory, Andrews, Robinson \& Hoge, 1984; Youth Level of Service/Case Management Inventory; Hoge \& Andrews, 2002; Young Offender Assessment Profile, Youth Justice Board, 2006) have been 
designed to identify those characteristics of the individual and their situation which impact systematically on behaviour and thereby guide decision-making about risk management.

\section{ACKNOWLEDGEMENT}

Sections of this paper have been previously published in a report for the South Australian Guardian for Children and Young People entitled Review of Programmes in Youth Training Centres.

\section{REFERENCES}

Andrews, D. A., \& Bonta, J. (1998). The psychology of criminal conduct. Cincinnati, OH: Anderson.

Andrews, D. A., Robinson, D., \& Hoge, R.D. (1984). Manual for the Youth Level of Service Inventory. Ottawa, Canada: Department of Psychology, Carleton University.

Ayers, C. D., Williams, J. H., Hawkins, J. D., Peterson, P. L., Catalano, R. F. \& Abbott, R. D. (1999). Assessing correlates of onset, escalation, deescalation and desistence of delinquent behavior. Journal of Quantitative Criminology, 15(3), 277-306.

Bohm, R. (2001). A primer on crime and delinquency theory. Belmont, CA: Wadsworth.

Bronfenbrenner, U. (1979). The ecology of human development: Experiments by nature and design. Cambridge, MA: Harvard University Press.

Caspi, A., \& Moffitt, T. E. (1995). The continuity of maladaptive behavior: From description to understanding in the study of antisocial behavior. In D. Cicchetti \& D. J. Cohen (Eds.), Developmental psychopathology Volume 2: Risk, disorder, and adaptation (pp. 472-511). New York: Wiley.

Catalano, R. F., \& Hawkins, J. D. (1996). The Social Development Model: A theory of antisocial behavior. In J.D. Hawkins (Ed.), Delinquency and crime: Current theories (pp. 149-197). New York: Cambridge University Press.

Catalano, R. F., \& Kosterman, R. (1996). Modelling the etiology of adolescent substance use: A test of the social development model. Journal of Drug Issues, 26 (2), 429-455.

Cullen, F. T., \& Agnew, R. (Eds.), (2003). Criminological theory: Past to present. Los Angeles: Roxbury.

Cullen, F. T., \& Gendreau, P. (2000). Assessing correctional rehabilitation: Policy, practice, and prospects. In J. Horney (Ed.), Criminal Justice 2000: Volume 3 - Policies, processes, and decisions of the Criminal Justice System (109-175). Washington, DC: US Department of Justice, National Institute of Justice.

Eisenberg, N., Zhou, Q., \& Koller, S. (2001). Brazilian adolescents' prosocial moral judgment and behavior: Relations to sympathy, perspective taking, gender-role orientation and demographic characteristics". Child Development, 72, 518-34.

Engler, E. (2008). Personality theories (6 $6^{\text {th }}$ ed.). Boston: Houghton Mifflin Company.

Fagan, J., \& Wesler, S. (1988). Explanations of sexual assault among violent delinquents. Journal of Adolescent Research, 3, 363-385.

Falshaw, L., Friendship, C., Travers, R., \& Nugent, F. (2003) Searching for 'What Works': An evaluation of cognitive skills programmes. Home Office Research Findings 206. London: Home Office.

Farnworth, M., \& Leiber, M. J. (1989). Strain theory revisited: Economic goals, educational means, and delinquency. American Sociological Review, 55 (2), 236-279.

Farrington, D. P. (1992). Expaling the beginning, progress and ending of antisocial behavior from birth to adulthood. In J. McCord (Ed.), Facts, frameworks and forecasts: Advances in criminological theory (Vol. 3, pp1253-286). New Brunswick, NJ: Transaction Publishers.

Farrington, D. P. (1995a). The challenge of teenage antisocial behavior. In M. Rutter (Ed.), Psychosocial disturbances in young people: challenges for prevention ( $\mathrm{pp}$ 83-130). Cambridge, UK: Cambridge University Press.

Farrington, D. P. (1995b). The development of offending and antisocial behavior from childhood: Key findings from the Cambridge Study in Delinquent Development. Journal of Child Psychology and Psychiatry, 36, 929-964.

Farrington, D. P. (2000). Explaining and preventing crime: The globalization of knowledge: The American Society of Criminology 1999 presidential address. Criminology, 38 (1), 1-24.
Farrington, D. P. (2003). Key results from the first 40 years of the Cambridge Study in Delinquent Development. In T. P. Thornberry \& M. D. Krohn (Eds.), Taking stock of delinquency: An overview of findings from contemporary longitudinal studies (pp.137-183). New York: Kluwer-Plenum.

Farrington, D. P. (Ed.). (2005a). Integrated developmental and life-course theories of offending. New Brunswick, NJ: Transaction Publishers.

Farrington, D. P. (2005b). Childhood origins of antisocial behavior. Clinical Psychology and Psychotherapy, 12, 177-190.

Farrington, D. P. (2007). Advancing knowledge about desistance. Journal of Contemporary Criminal Justice, 23 (1), 125-134.

Ford, D. L., \& Lerner, R. M. (1992). Developmental systems theory: An integrative approach. Newberry Park, CA: Sage.

Gendreau, P., Goggin, C. Cullen, F. T., \& Andrews, D. A. (2000). The effects of community sanctions and incarceration on recidivism. Forum on Corrections Research, 12, 10-13.

Glueck, S., \& Glueck, E. T. (1950). Unravelling juvenile delinquency. New York: Commonwealth Fund.

Hagell, A. (2002). The mental health of young offenders - bright futures: Working with vulnerable young people. London, UK: Mental Health Foundation.

Henry, B., Caspi, A., Moffitt, T. E., \& Silva, P. A. (1996). Temperamental and familial predictors of violent and non-violent criminal convictions: Age 3 to 18. Developmental Psychology, 32, 614-623.

Hoge, R. (2001). The juvenile offender: Theory, research and applications. Norwell, MA: Kluwer Plenum.

Hoge, R. D., \& Andrews, D.A. (2002). Youth Level of Service/Case Management Inventory: User's Manual. Toronto, Canada: Multi Health Services.

Howell, J. C., \& Lipsey, M. W. (2004). A practical approach to evaluating and improving juvenile justice programs. Juvenile and Family Court Journal, 55 (1), 35-48.

Latessa, E.J., Cullen, F.t., \& Gendreau, P. (2002). Beyond correctional quackery: Professionalism and the possibility of effective treatment. Federal Probation, 66 (2), 43-49.

Lipsey, M. W. (2005). What works in juvenile offenders: Translating research into practice. Presented at the Adolescent Treatment Issues Conference, Tampa, FL. Available from: http://www.tyc.state.tx.us/ archive/ Research/TxmtEffect05/15_references.html

Lipsey, M., \& Wilson, D. (1998). Effective intervention for serious juvenile offenders: A synthesis of research. In R. Loeber \& D. P. Farrington (Eds.), Serious and violent juvenile offenders: Risk factors and successful interventions (pp. 313-345). Thousand Oaks, CA: Sage.

Loeber, R., Stouthamer-Loeber, M., Van Kammen, W. B., \& Farrington, D. P. (1991). Initiation, escalation and desistance in juvenile offending and their correlates. Journal of Criminal Law and Criminology, 82, 36-82

Loeber, R., \& Le Blanc, M. (1990). Toward a developmental criminology. In M. Tonry and M. Norris (Eds.), Crime and justice: A review of research, Volume 12 (pp. 375-473). Chicago: Chicago University Press.

Losel, F. (1995). Increasing consensus in the evaluation of offender rehabilitation? Lessons from recent research syntheses. Psychology, Crime and Law, 2, 19-39.

McCabe, K. M., Hough, R., Wood, P. A., \& Yeh, M. (2001). Childhood and adolescent onset conduct disorder: A test of the developmental taxonomy. Journal of Abnormal Child Psychology, 29, 305-316.

McGuire, J. (2002). Explanations of criminal behavior. In J. McGuire, T. Mason, \& A. O'Kane (Eds.), Behavior, crime and legal processes: A guidebook for practitioners. Chichester: Wiley.

Moffitt, T. E. (1993). Adolescence-limited and life-course persistent antisocial behavior: A developmental taxonomy. Psychological Review, 100 (4), 674-701.

Moffitt, T. E. (1997). Adolescent-limited and life-course persistent offending: A complementary pair of developmental taxonomies. In In T.P. Thornberry (Ed.), Advances in criminological theory (Vol. 7): Developmental theories of crime and delinquency (pp.11-54). New Brunswick, NJ: Transaction Publishers.

Moffitt, T. E. \& Caspi, A. (2001). Childhood predictors differentiate lifecourse persistent and adolescence-limited antisocial pathways among males and females. Development and Psychopathology, 13, 355-375.

Moffitt, T. E., Lynam, D. R., \& Silva, P.A. (1994). Neuropsychological tests predicting persistent male delinquency. Criminology, 32, 277-300.

Nagin, D. S., Farrington, D. P., \& Moffitt, T. W. (1995). Life-course trajectories of different types of offenders. Criminology, 22, 111-139.

Piquero, A. R. \& Brezina, T. (2001). Testing Moffitt's account of adolescence-limited delinquency. Criminology, 39, 353-370. 
Raftery, S. (2005). Differences in adolescent risk-taking behavior. Unpublished Honours dissertation, University of South Australia.

Sameroff, A .J. (1983). Developmental systems: Contexts and evolution. In W. Kessen (Ed.), Handbook of child psychology (Vol. 1): History, theory and methods (pp.237-294). New York: Wiley.

Sampson, R. J., \& Laub, J. H. (1993). Crime in the making: Pathways and turning points through life. Cambridge, MA: Harvard University Press.

Sampson, R. J., \& Laub, J. H. (1997). A life-course theory of cumulative disadvantage and stability of delinquency. In In T.P. Thornberry (Ed.), Advances in criminological theory (Vol. 7): Developmental theories of crime and delinquency (pp.133-162). New Brunswick, NJ: Transaction Publishers.

Sampson, R. J., \& Laub, J. H. (2003). Life-course desisters? Trajectories of crime among delinquent boys followed to age 70. Criminology, 41, 301-339.

Sampson, R. J., \& Laub, J. H. (2005). A life-course view of the development of crime. The Annals of the American Academy of Political and Social Science, 602 (1), 12-45.
Shields, I. (1993). The use of the young offender-level of service inventory with adolescents. The Jarca Journal, 8-9.

Thornberry, T. P. (1997). Introduction: Some advantages of developmental and life-course perspectives for the study of crime and delinquency. In T.P. Thornberry (Ed.), Advances in criminological theory (Vol. 7): Developmental theories of crime and delinquency (pp.1-10). New Brunswick, NJ: Transaction Publishers.

Tobach, E., \& Greenberg, G. (1984). The significance of T.C. Schneirla's contribution to the concept of levels of integration. In E. Tobach (Ed.), Behavioral evolution and integrative levels (pp.1-8). Hillsdale, NJ: Erlbaum.

Yoshikawa, H. (1994). Prevention as cumulative protection: Effects of early family support and education on chronic delinquency and its risks. Psychological Bulletin, 115, 28-54.

Youth Justice Board (1999). ASSET Assessment Profile. London: Author.

Received: March 11, 2011

Revised: May 25, 2011

Accepted: May 25, 2011

(C) Sharon Casey; Licensee Bentham Open.

This is an open access article licensed under the terms of the Creative Commons Attribution Non-Commercial License (http://creativecommons.org/licenses/by-nc/3.0/) which permits unrestricted, non-commercial use, distribution and reproduction in any medium, provided the work is properly cited. 